СМИРНОВ Алексей Николаевич - кандидат политических наук, старший научный сотрудник Национального исследовательского института мировой экономики и международный отношений им. Е.М. Примакова (117997, Россия, г. Москва, ул. Профсоюзная, 23; alexmirnew@таil.ru)

\title{
ПОЛИТИЧЕСКИЕ ЗАБОТЫ И «СЕМЕЙНЫЕ ПРОБЛЕМЫ» ЕВРОПЕЙСКИХ ПРАВЫХ ЦЕНТРИСТОВ НА ФОНЕ КОРОНАВИРУСНОГО КРИЗИСА
}

\begin{abstract}
Аннотация. В статье рассматривается реакция европейских политиков правоцентристского толка на угрозы, сопряженные с распространением коронавирусной инфекции. Основное внимание сосредоточено на политическом контексте восприятия проблемы. Охватившая Европу пандемия коронавируса сопровождалась острым дефицитом доверия руководству ЕС. Возникающие разногласия стали дополнительным стимулом для роста оппозиционных настроений внутри Европейской народной партии, которая наиболее последовательно отстаивает приоритеты интеграционного проекта. Особую озабоченность лидеров партии вызывают действия премьер-министра Венгрии Виктора Орбана - харизматичного консерватора, имеющего свой взгляд на перспективы развития европейского правого центризма. Венгерский пример демонстрирует сложность отношений внутри европейской христианско-демократической «семьи» и является показателем кризисного состояния, в котором находится умеренный консерватизм.
\end{abstract}

Ключевые слова: Евросоюз, коронавирусный кризис, правый центризм, Европейская народная партия, интеграция, национализм, европейский проект, солидарность, Венгрия, Виктор Орбан, консерватизм

B настоящей статье рассматривается реакция европейских политиков правоцентристского толка на угрозы, сопряженные с распространением коронавирусной инфекции. Охватившая Европу пандемия коронавируса, сопровождаемая острым дефицитом доверия руководству ЕС, стала дополнительным стимулом для роста оппозиционных настроений внутри Европейской народной партии (ЕНП) - умеренно консервативного альянса, на протяжении многих лет выступавшего ведущей политической силой в Евросоюзе, а в идеологическом плане - институционально оформленной основой европейской христианско-демократической «семьи».

K концу 2019 г. политическая повестка европейских правоцентристов, по-прежнему занимающих наиболее прочные позиции в руководстве ЕС, включала ряд актуальных вопросов, каждый из которых в той или иной мере затрагивал сложившуюся систему представлений о демократических устоях и конфигурации власти в Евросоюзе. Среди предметов особой озабоченности фигурировали затянувшийся Брексит, сохранение международных позиций EC, в т.ч. непростые отношения с США, поддержание согласованной санкционной политики в отношении России, достижение общеевропейского единства в сфере политики расширения ЕС, набирающий силу приток новой волны иммигрантов из стран Ближнего Востока. Перечисленные проблемы, значимые сами по себе, создали дополнительное бремя для консерваторов из ЕНП, являясь источниками возрастающего влияния их политических оппонентов.

Описанная ситуация задала общее направление дискуссии на очередном, 24-м съезде Европейской народной партии, открывшемся 20 ноября 2019 г. в Загребе. Делегаты съезда избрали нового президента партии. Им стал видный представитель польской либерально-консервативной партии «Гражданская платформа» Дональд Туск, на момент избрания готовившийся покинуть пост 
главы Европейского совета, а ранее длительное время возглавлявший правительство Польши.

Выступая на партийном форуме, новоизбранный лидер констатировал тесную взаимосвязь, существующую между актуализацией национально-государственной идентичности европейцев и возрастающими требованиями к их безопасности. По его словам, до недавнего времени безопасность и идентичность, генерируемые государственной властью, воспринимались как достояние прошлого, имеющее неочевидную значимость для последующих поколений. Реальность опровергает подобные прогнозы. Сегодня страх играет все более заметную роль в политике, превалируя над другими социальными эмоциями. Острую нехватку безопасности провоцируют атаки террористов и перманентный миграционный кризис. В условиях нарастающей неопределенности особенно велик спрос на решительных и уверенных политиков, все громче звучат голоса тех, кто, апеллируя к национальному достоинству и ценностям государственного суверенитета, предлагает простые рецепты избавления от проблем. Противодействие националистам Туск считает одной из основных задач возглавленной им партии: «Ни при каких обстоятельствах мы не можем отдать сферу безопасности и порядка политическим популистам, манипуляторам и автократам, которые заставляют людей поверить, что свободу нельзя примирить с безопасностью, а защиту границ и территорий - с либеральной демократией» 1 .

Дональд Туск назвал приоритетность гражданских прав и свобод основной темой внутренних дебатов в Европейской народной партии. По его убеждению, не является христианским демократом тот, кто выступает против правовой государственности, независимой юстиции, свободной прессы и неправительственных организаций. При этом Туск заметил, что деятели, готовые поступиться идеалами правового государства и открытого общества, принеся их в жертву «на алтаре безопасности и порядка», «де факто ставят себя вне пределов нашей семьи» ${ }^{2}$. Последний пассаж явно касается идейного противоборства между руководством ЕНП и премьер-министром Венгрии Виктором Орбаном - лидером входящей в правоцентристский альянс партии «Фидес», который, будучи убежденным консерватором, не только демонстративно пренебрегает требованиями ЕС, но и бросает системный вызов политике Брюсселя.

С началом острой фазы кризиса, вызванного распространением в Европе коронавирусной инфекции, прежде существовавшие опасения за судьбу интеграционного проекта подтвердились и усилились. Серьезным поводом для этого послужила явная неготовность европейских институтов к столь тяжким испытаниям и неспособность оперативно координировать действия государств-членов, поодиночке приступивших к отражению пандемии.

В создавшихся условиях политический курс Виктора Орбана стал объектом особенно жесткой критики со стороны европейских властей как примерутверждения ложной альтернативы между свободой и безопасностью. Вызывающее поведение Будапешта послужило формальным основанием для очередной попытки исключения венгерской правящей партии «Фидес» из рядов ЕНП, которая была предпринята в первых числах апреля 2020 г. после того, как 30 марта парламент Венгрии одобрил расширение полномочий правительства

\footnotetext{
1 Tusk D. 2019. Speech by President Tusk at EPP Congress. Zagreb, 20 November 2019. - The European People's Party. Press Releases. 20.11.2019. URL: https://www.epp.eu/press-releases/ speech-by-president-at-epp-congress/ (accessed 11.11.2020).

2 Ibid.
} 
Орбана на неопределенный срок в связи с пандемией коронавируса. Дональд Туск выступил с острой критикой действий венгерских властей, изложив свою позицию в открытом письме членам ЕНП. По словам автора письма, в настоящее время приоритетом является борьба с пандемией, но скоро придет время вновь поднять вопрос об исключении венгерского «Фидес» из «Европейской народной партии». Дональда Туска в данной ситуации гораздо больше беспокоит проблема соответствия действий венгерского премьера комплексу «демократических ценностей», вменяемых в качестве поведенческий нормы всякому политическому субъекту в пределах ЕС или в зоне европейского влияния. Вердикт бывшего польского премьера трудно оспорить: «Использование пандемии для создания долгосрочного чрезвычайного положения является политически опасным и морально неприемлемым» 1 .

Вместе с тем сложность положения, в котором оказалось руководство ЕНП, усугубляется тем, что «Фидес», наряду с германским Христианскодемократическим союзом (ХДС), остается одной из крупнейших партий в альянсе, влияющей на его присутствие в Европарламенте, а Виктор Орбан выступает не только как своевольный лидер государства с автократическими наклонностями, но и как консервативный оппозиционер, имеющий свой взгляд на перспективы развития европейского правого центризма. В феврале 2020 г., когда Европа с опаской наблюдала за вспышкой неведомой инфекции в китайском Ухане, «венгерский бунтарь» представил лидерам ЕНП меморандум с предложением изменить стратегический курс партии.

Документ открывается довольно пространным рассуждением о пути, пройденном Европейской народной партией за минувшие десятилетия, и о ее состоянии на данный момент. Состояние это оценивается весьма критически. На взгляд автора меморандума, ЕНП была очень активной в начале своего политического пути и сыграла важную роль в европейских общественных дебатах. Партия оформила мнение большинства, решительно выступая за демократию, антикоммунистическую рыночную систему, субсидиарные, антибюрократические отношения, отстаивала приверженность традиционной семье - вдохновленному христианством союзу мужчины и женщины. Перечисленные ценности она «смело, гордо и успешно» представляла в Европе и мире. Происшедшие с тех пор перемены привели к вопиющему искажению идейного облика и политической сути Европейской народной партии. Вместо христианско-демократической модели устройства общества продвигаются эгалитарные социальные теории, вместо стремления к субсидиарности происходит усиление бюрократии и централизации в Брюсселе. Следствием всего перечисленного является размывание электоральной базы ЕНП. С общим негативным фоном происходящих изменений связывается и заметный спад влияния партии на европейской политической арене, который действительно происходит вне зависимости от субъективных оценок ${ }^{2}$.

В обозначенном проблемном контексте Орбан предложил провести внутренние дебаты о будущей миссии ЕНП. Идейное упорство и решимость венгерского лидера подчеркивается рядом его высказываний. Например, в июле 2019 г. он объявил борьбу с либеральной демократией своим основным политическим проектом на следующие 15 лет, предельно конкретно обозначив

\footnotetext{
1 Fidesz zostanie wykluczony z Europejskiej Partii Ludowej? Tusk napisał list do członków ugrupowania. - TygodnikSolidarność.01.04.2020.Доступ:https://tysol.pl/a45706-Fidesz-zostaniewykluczony-z-Europejskiej-Partii-Ludowej-Tusk-napisal-list-do-czlonkow\%C2\%A0ugrupowania (проверено 11.11.2020).

2 Orbán Pens Memo Calling for EPP Reform. 2020. - Hungary Today. 19.02.2019. URL: https://hungarytoday.hu/orban-pens-memo-calling-for-epp-reform/ (accessed 11.11.2020).
} 
столь долгосрочную задачу: «Осуществимо, возможно и разумно противопоставить тезис о нелиберальной демократии тезису о либеральной демократии не только интеллектуально, но и как политическую программу» ${ }^{1}$.

Проявляя завидную активность во всех европейских делах и ратуя за идейное «возрождение» Европейской народной партии, венгерский премьер, тем не менее, остается националистом, причем не только по убеждениям, но и, если можно так выразиться, по «роду деятельности». Это наглядно демонстрирует поведение венгерских властей в разгар коронавирусного кризиса. Как свидетельствуют данные Европейского совета по международным отношениям, с начала марта Венгрия показала себя очень активной в проявлениях антикризисной солидарности [Végh 2020]. Она чаще других стран EC, за исключением Франции и Германии, участвовала в акциях взаимопомощи, чем заслужила репутацию передового борца с коронавирусной опасностью. С самого начала применив сепаратную стратегию противодействия COVID-19 и сделав ставку на использование комплекса ответных мер «национального формата», Венгрия продолжила делать то, что с успехом осуществляла ранее, - создавать геополитический и этнокультурный плацдарм в своем ближнем зарубежье, только теперь с учетом стимулирующего фактора ковидной угрозы. Адресуя помощь в основном соседним государствам, Будапешт инвестировал в поддержку венгерских этнических меньшинств, а также в обеспечение стратегически важной для себя стабильности на Балканах, причем помощь получили не только соседи по ЕС, но и не входящие в Евросоюз страны: Сербия, Северная Македония, Черногория, Босния и Герцеговина. Такая широта в распространении пожертвований объяснятся не столько великодушием венгерской стороны, сколько стремлением поддержать государства, способные выступить «внешним санитарным кордоном» при практически неизбежном наплыве мигрантов. Практическое обоснование принятых мер дал министр иностранных дел Венгрии Петер Сиярто. Объявляя о помощи Северной Македонии, он сказал: «Мы, венгры, заинтересованы в том, чтобы линия эффективной защиты от миграционного давления была как можно дальше на юг»².

Надо отдать должное Виктору Орбану: у него как у политика не только идейного, но и практического склада нет проблем со смысловым наполнением и практической реализацией выдвигаемых лозунгов. Показателем чрезвычайной сложности его взаимоотношений с правоцентристским истеблишментом являются периодические «внутрипартийные» конфликты, зачастую приобретающие личный характер. Все они в той или иной степени отражают глубокие противоречия, существующие между Брюсселем и Будапештом. В частности, можно упомянуть, что поводом для временного исключения венгерской «Фидес» из состава ЕНП в марте 2019 г. послужила медиакампания, проведенная партией Орбана, против поощрения нелегальной миграции в Европу. Основными объектами критики при этом выступили международные структуры Джорджа Сороса, действующие заодно с институтами ЕС. Наибольший резонанс вызвало размещение на венгерских улицах билбордов с изображениями тогдашнего главы Еврокомиссии представителя ЕНП Жан-Клода Юнкера

\footnotetext{
1 Orbán's full speech at Tusványos: political philosophy, upcoming crisis and projects for the next 15 years. 2019. - Visegrád Post. 29.07.2019. URL: https://visegradpost.com/en/2019/07/29/ orbans-full-speech-at-tusvanyos-political-philosophy-upcoming-crisis-and-projects-for-thenext-15-years/ (accessed 11.11.2020).

${ }^{2}$ Hungary is helping North Macedonia with protective equipment. 2020. - Ministry of Foreign Affairs and Trade. Website of the Hungarian Government. 01.04.2020. URL: https://2015-2019. kormany.hu/hu/kulgazdasagi-es-kulugyminiszterium/hirek/magyarorszag-vedofelszerelesselsegiti-eszak-macedoniat (проверено 15.11.2020).
} 
и Сороса, сопровождаемых подписями: «Они хотят ослабить государства ЕС» и «Кто знает, что еще готовит Брюссель?» Подобная акция была воспринята в руководстве ЕНП как действия, наносящие ущерб имиджу партии в преддверии выборов в Европарламент ${ }^{1}$. Реакция оказалась настолько болезненной, что спустя 9 месяцев в своей инаугурационной речи, произнесенной на партийном съезде в Загребе, Дональд Туск нашел повод едко высказаться о действиях венгерских пропагандистов. Высоко оценив усилия, приложенные его партийными коллегами к преодолению миграционного кризиса, он заметил: «Кое-кто тоже усердно работал, но только над своим имиджем, выставив забор и рекламные щиты с антимиграционной пропагандой» ${ }^{2}$.

Несмотря на моральное давление противников, власти Венгрии, как и близкое им по духу руководство Польши, сосредоточенное в руках правоконсервативной партии «Право и справедливость» (ПиС), чувствуют себя в относительной безопасности от любых практических мер со стороны Брюсселя, призванных пресечь систематическое игнорирование базовых принципов европейского устройства. Очевидно, у руководства ЕС нет реальных инструментов воздействия на «провинившиеся» режимы, во всяком случае таких, которые можно было бы применить, не ставя под угрозу порядок, заведенный в «европейском доме» с момента его основания. Евросоюз является добровольным альянсом суверенных государств, и механизм введения санкций против отдельной страны слишком сложен, чтобы применять его на практике. Институциональная структура ЕС изначально не была рассчитана на противодействие политике стран-членов, приверженных идее единой Европы (хотя и в своей особой трактовке), но довольно радикально отходящих от «общепринятых» либеральных основ демократического устройства.

За отсутствием иных средств Еврокомиссия еще в 2018 г. предложила разрешить Брюсселю приостанавливать выплаты из бюджета ЕС странам, не соблюдающим принцип верховенства права. Разумеется, уже на тот момент под «нарушителями» подразумевались Варшава и Будапешт. В марте 2019 г., когда венгерская партия «Фидес» оказалась временно исключенной из Европейской народной партии, тогдашний лидер фракции ЕНП в Европарламенте и кандидат на пост главы Еврокомиссии Манфред Вебер объявил о своей убежденности в том, что партии евроскептиков не должны больше иметь право получать средства из ЕС. Он также пригрозил ограничить доступ Венгрии к фондам ЕС в случае каких-либо неправовых действий со стороны ее властей ${ }^{3}$.

Коронавирусный кризис, разразившийся в разгар работы над бюджетом Евросоюза, придал дополнительную весомость угрозам, исходящим из Брюсселя. Со своей стороны Варшава и Будапешт приложили максимально возможные усилия, дабы предложенные руководством ЕС финансовые механизмы не заработали. Против инициативы германской стороны на словах выступил даже действующий председатель ЕНП Дональд Туск, которого никак нельзя заподозрить в симпатиях к Орбану, и особенно к «землякам» из польской правящей партии «Право и справедливость». По словам политика, он

\footnotetext{
${ }^{1}$ Decision of the EPP Political Assembly regarding the EPP Membership of Fidesz. 2019. - The European People's Party. Declarations. 20.03.2019. URL: https://www.epp.eu/papers/proposalof-the-epp-presidency-to-the-political-assembly-regarding-the-epp-membership-of-fidesz/ (accessed 11.11.2020).

2 Tusk D. 2019. Speech by President Tusk at EPP Congress. Zagreb, 20 November 2019. - The European People's Party. Press Releases. 20.11.2019. URL: https:/www.epp.eu/press-releases/ speech-by-president-at-epp-congress/ (accessed 11.11.2020).

3 Vass A. 2019. Weber Increases Pressure on Fidesz. - Hungary Today. 28.03.2019. URL: https:// hungarytoday.hu/weber-increases-pressure-on-fidesz/ (accessed 11.11.2020).
} 
эмоционально не в состоянии размышлять о санкциях ввиду тяжести ситуации, сложившейся в ЕС. Кроме того, замечает Туск, «не граждане виноваты в антидемократичных действиях в их столицах, поэтому мы не должны их наказывать» 1

Основная борьба вокруг положения о политическом допуске к получению средств ЕС должна была развернуться 17-18 июля на первом с начала 2020 г. очном саммите Евросоюза, где одновременно обсуждались семилетний бюджет и «фонд восстановления». Последний, вызывающий наиболее бурную дискуссию, направлен на преодоление последствий коронавирусного кризиса для европейской экономики.

За несколько дней до начала саммита Виктор Орбан провел через подконтрольный парламент поручение правительству голосовать против изобретенной Брюсселем «финансовой западни». Не имея реальных возможностей повлиять на принятие уже согласованных решений, заинтересованные страны - Венгрия и Польша - пригрозили наложить вето на сам бюджет при попытке увязать финансовую помощь с политическими вопросами, и это, кажется, сработало. Во всяком случае, если данная тема и обсуждалась, то вскользь, лишь в дополнение к иным, более значимым проблемам, послужившим предметом острых прений и затянувшим встречу вдвое по сравнению с ранее намеченным сроком. Необходимость учитывать политическую составляющую при распределении финансов, в частности, пытался обосновать премьер-министр Нидерландов Макс Рютте, чем вызвал гневную отповедь со стороны Виктора Орбана, который в присущей ему манере был очень активен и отнюдь не собирался становиться объектом чьего-либо осуждения ${ }^{2}$.

Описанная ситуация показывает, насколько сложно доминирующим в ЕС силам что-то противопоставить политическим «отщепенцам». Националконсервативный проект Виктора Орбана продолжает развиваться, несмотря на угрозы отлучения Венгрии от программы финансовой помощи и окончательного изгнания «Фидес» из рядов ЕНП. Возможно, реализовать эти угрозы мешает чрезвычайная обстановка, вызванная коронавирусным кризисом, но и ранее либерально-консервативному истеблишменту приходилось терпеть своеволие скандального «полудиктатора», нашедшего свое весьма заметное место в структуре отношений внутри Евросоюза. Как бы то ни было, потенциальная «заразительность» венгерского примера вызывает все больше опасений у европейского руководства.

\section{Список литературы}

Végh Z. 2020. Instrumental solidarity: Hungary's management of the coronavirus crisis: commentary. - European Council on Foreign Relations. 01.07.2020. URL: https://www.ecfr.eu/article/commentary_instrumental_solidarity_hungarys_management_of_the_coronavirus_c (accessed 11.11.2020).

1 Tusk D. 2020. Was die Wirtschaft angeht, brauchen wir einen Blitzkrieg. Ein Interview von Peter Müller und Jan Puhl. - Der Spiegel. 16.04.2020. Доступ: https://www.spiegel.de/politik/ ausland/donald-tusk-was-die-wirtschaft-angeht-brauchen-wir-einen-blitzkrieg-a-e46f8eb9-426f4f83-bbfe-6600c18391c5 (проверено 11.11.2020).

2 Bayer L., Von der Burchard H. 2020. Viktor Orbán: I don’t know why Mark Rutte hates me and Hungary. - Politico. 20.07.20. URL: https://www.politico.eu/article/viktor-orban-i-dont-knowwhy-mark-rutte-hates-me-and-hungary/ (accessed 11.11.2020). 
SMIRNOV Aleksey Nikolaevich, Cand.Sci. (Pol.Sci.), Senior Researcher at the Primakov Institute of World Economy and International Relations, Russian Academy of Sciences (23 Profsojuznaja St, Moscow, Russia, 117997; alexmirnew@ mail.ru)

\title{
POLITICAL CONCERNS AND «FAMILY PROBLEMS» OF THE EUROPEAN RIGHT-WING CENTRISTS IN THE CONTEXT OF THE CORONAVIRUS CRISIS
}

\begin{abstract}
The article examines the reaction of European right-wing centrist politicians to the threats associated with the spread of coronavirus infection. The author focuses the main attention on the political context of the problem perception. The coronavirus pandemic that gripped Europe was accompanied by an acute deficit of confidence in the EU leadership. The resulting disagreements have become an additional incentive for the growth of opposition sentiments within the European People's Party, which most consistently defends the integration project priorities. The party leaders are especially concerned about the actions of the Hungarian Prime Minister Viktor Orban, which is a charismatic conservative who has his own view of the prospects for the development of European right-wing centrism. The Hungarian example demonstrates the complexity of relations within the European Christian-Democratic "family" and is an indicator of the state of crisis in which moderate conservatism finds itself.
\end{abstract}

Keywords: European Union, coronavirus crisis, right-wing centrism, European People's Party, integration, nationalism, European project, solidarity, Hungary, Viktor Orban, conservatism 